\title{
O LOBO VEGETARIANO E O CORDEIRO NO BANQUETE DE FORRAGEM: A UTOPIA DA SUPERAÇÃO DO ANTAGONISMO ENTRE CAPITAL E TRABALHO
}

\author{
Hilda Baião Ramirez Deleito ${ }^{1}$
}

\begin{abstract}
Resumo: A reforma trabalhista vem sendo normalmente apresentada como uma ruptura neoliberal com a tradição de protecionismo da Justiça do Trabalho e da legislação referente ao tema. Existe, todavia, um elemento de continuidade, que é a persistência na promessa da paz perpétua. A CLT apresenta a fraternidade entre as classes como imposição cristã. A Reforma Trabalhista insiste na superação dos conflitos como imposição da democracia, uma vez removida a intervenção estatal representada pela justiça do trabalho. Trata-se de uma utopia, uma vez que as classes antagonistas disputam recursos limitados na luta pela sobrevivência.
\end{abstract}

Palavras-chave: reforma trabalhista; superação dos conflitos; utopia.

\section{THE VEGETARIAN WOLF AND THE LAMB AT THE FORAGE BANQUET: THE UTOPIA OF OVERCOMING ANTAGONISM BETWEEN CAPITAL AND LABOR}

\begin{abstract}
Labor reform has usually been presented as a neoliberal break with the protective tradition of of both labour justice and labour legislation. There is, however, an element of continuity, which is persistence in the promise of pax perpectua. The CLT presents the fraternity among the classes as Christian commandment. Labour reform insists that overcoming conflicts is dictated by democratic ideals, once the state intervention represented by the labour justice is removed. It is utopic, as antagonistic classes struggle for survival and limited resources.
\end{abstract}

Keywords: Labor reform; conflict overcoming; utopia.

\section{A utopia da paz perpétua}

Em seu anúncio da paz messiânica, o profeta Isaías prometeu um futuro de justiça, no qual seria possível que "o lobo morará com o cordeiro e o leopardo se deitará com o cabrito. O bezerro, o leãozinho e o gordo novilho andarão juntos e um menino pequeno os guiará”. Essa paz perpétua, extensiva aos animais pressupõe um governo de justiça e equidade, para que o

\footnotetext{
${ }^{1}$ Doutoranda em Direito pela Universidade Veiga de Almeida, Mestre em Direito pela Universidade Candido Mendes. Bacharel em Direito pela Universidade Santa Úrsula, graduada e licenciada em História pela Pontifícia Universidade Católica do Rio de Janeiro. Analista judiciário no Tribunal Regional do Trabalho da 1a Região.
} 
cordeiro não tenha motivos de queixa contra o lobo (nem vice-versa, naturalmente), mas o fim do estado de necessidade. Assim não só o “leão se alimentará de forragem como o boi”, mas ambos terão forragem suficiente para satisfazer às suas necessidades. Essa profecia foi escrita antes da Era Cristã, quando os israelitas disputavam um pequeno território parcialmente desértico no Oriente Médio com povos de nomes exóticos (jebuseus, amorreus, filisteus, etc). E nos parecem exóticos justamente porque perderam a luta pela sobrevivência enquanto povo. Mas a esperança declarada por Isaías, de uma paz perpétua inspirada pela justiça, equidade e recursos suficientes para a sobrevivência de todos ainda persiste, ainda que despojada de sua inspiração religiosa.

Recentemente, a exposição de motivos da lei $n^{\circ}$ 13.467/2017 propôs justamente uma releitura dessa utopia, sob a forma de um mercado de trabalho em que o lobo capitalista se concilia com o cordeiro proletário e, por conseguinte, prescindem da intervenção estatal (Justiça do Trabalho). Uma perspectiva neoliberal inverteria as posições, nomeando o capitalista como cordeiro e os sindicatos como o lobo. Qualquer que seja a perspectiva, o fato é que a Reforma pretende tornar a Justiça do Trabalho despicienda na resolução de conflitos, porque todo o antagonismo será superado naturalmente por comissões mistas de empregadores e empregados.

A reforma trabalhista vem sendo normalmente apresentada como uma ruptura neoliberal radical com o protecionismo que norteia a CLT e a atuação do judiciário. E de fato estamos inquestionavelmente diante do primeiro passo na desconstrução do arcabouço protetivo formulado pela CLT e recepcionado pela Constituição Federal. É um passo modesto, diante da dificuldade de uma reforma constitucional prejudicial aos interesses dos trabalhadores tão próxima a um ano eleitoral. Ditado pela necessidade de reverter as elevadas taxas de desemprego e criar uma agenda positiva para uma gestão marcada pela impopularidade.

As novas vagas de emprego não se materializaram, apesar das possibilidades abertas pela regulamentação do trabalho intermitente. Apesar da facilidade proporcionada pelas contratações precárias, agora legalizadas, o desemprego em fevereiro de 2018 atingiu 13,1 milhões de pessoas. Esse resultado negativo vem sendo minimizado diante da redução na litigiosidade na Justiça do Trabalho, que chegaria a 56,9\% por estimativas otimistas. Trata-se, contudo, de um engano perceber nessas estatísticas um progresso no sentido de um consenso racional entre interesses antagônicos.

O conflito é inerente às sociedades humanas. Os recursos são sempre limitados, consequentemente o conflito se instaura inevitavelmente. No mundo do trabalho, vagas de 


\section{O LOBO VEGETARIANO E O CORDEIRO NO BANQUETE DE FORRAGEM: A UTOPIA DA SUPERAÇÃO DO ANTAGONISMO ENTRE CAPITAL E TRABALHO}

emprego em condições decentes e com salários dignos são cada vez mais raras. A globalização impõe a extinção de modos tradicionais de sobrevivência. Populações inteiras se tornaram desnecessárias ao processo produtivo, e ainda mais se tornarão. A tecnologia também destruiu muitos empregos. Inclusive economistas reconhecem ser

concebível que, no futuro, muitas pessoas não terão quase nenhum valor econômico: não haverá nada que elas possam fazer que um robô não possa fazer com maior rapidez, segurança e confiabilidade, e a menor custo. Alguns humanos - talvez a maioria - não conseguirão competir e receber qualquer tipo de salário básico. Todos os proventos iriam para os donos do capital (HARTFORD, 2016, p. 269)

A EM no 00036/2016 MTB promove o entendimento direto entre trabalhadores e empregadores e afirma textualmente que já existiriam categorias profissionais que já prescindem da intermediação judicial na solução de suas controvérsias.

Entretanto, apesar da ruptura com o intervencionismo estatal nas relações de trabalho, a crença na utopia de uma conciliação entre antagonistas já havia sido expressa antes. A exposição de motivos da comissão copiladora da CLT igualmente apresentava o diálogo como imposição do humanismo cristão, a consolidação da "maturidade de uma ordem social” e do “espírito de equidade" no qual "confraternizaram as classes da vida econômica”. A mens legis de ambos os diplomas legais é a crença na utopia de paz perpétua, em que os desiguais viverão em perfeita harmonia e entendimento, e a intervenção estatal pode ser dispensada.

Não se ignora que o contexto histórico de ambos os diplomas legais é radicalmente diverso. No momento presente, estamos diante de um governo democrático, porém altamente impopular, que tenta reverter sua imagem negativa com uma agenda positiva, negociando “reformas”. Pretende igualmente demonstrar que não está inerte diante da crise econômica e do desemprego, e está adotando todas as previdências necessárias. A CLT, ao contrário, foi outorgada por um governo autoritário para conter o avanço de ideais anarquistas e comunistas no contexto de uma incipiente industrialização. Não se pretende minimizar, muito menos negar, o paradoxo de que o avanço nos direitos trabalhistas ocorreu durante um interregno autoritário, enquanto o atual retrocesso se dá em plena vigência da Constituição Cidadã de 1988. Apenas se pretende salientar ambas prometem uma harmonia utópica, que apenas pode se realizar no plano das ideias. No caso da atual Reforma Trabalhista, a utopia pode inclusive se transformar em distopia, diante do claro propósito de obstar a via judicial, sem a criação de alternativas viáveis.

\section{Hegelianos e humanistas}


O fim dos conflitos é uma releitura hegeliana da profecia messiânica, “uma paz eterna na qual todas as atividades especificamente humanas desapareceriam” (ARENDT, p. 348). Os marxistas, como seguidores da dialética hegeliana, nunca abandonaram a crença no fim da história, na plenitude do espírito que interrompe a marcha da história. A finalidade da história é o espírito conhecer a si mesmo, e quando alcança a plenitude do autoconhecimento, a história tem o seu fim. Segundo Hegel, o processo de desenvolvimento do espírito representa a reconciliação entre Deus e o Mundo, ao término do qual o último estará submetido a leis morais.

Segundo Hegel, ocorrerá uma reconciliação entre Deus e o Mundo (HEGEL, 2001, p. 342). O sofrimento é descrito como o confronto entre a dissolução do mundo e a perfeição do espírito (Deus). A agitação, na tradução inglesa de Hegel, unrest, vai acabar quando se reconciliarem os opostos, de um lado Deus/Espírito e do outro a realidade/mundo. Primeiramente, a reconciliação acontece na alma, mas no final dos tempos haverá uma regulação moral do mundo (HEGEL, 2001, p. 443). Nesse final dos tempos, a vida secular será a corporificação do Reino Espiritual, também chamado de Reino da Vontade (HEGEL, p. 462). Em sua conclusão, Hegel descreve a história do mundo, com todas as suas mudanças como o processo de desenvolvimento e realização do Espírito como uma "verdadeira Teodiceia, a justificação de Deus na História” (HEGEL, 2001, p. 477).

Essa conciliação entre antíteses (Deus/mundo) se apresenta claramente na exposição de motivos da CLT. A Consolidação das Leis do Trabalho, como as demais legislações de regulamentação do trabalho, surgiram como resposta à chamada “questão social”. Palma Ramalho ensina que a exploração do ser humano havia sido denunciada pela Igreja Católica (RAMALHO, 2009, p. 63) . Na Encíclica Rerum Novarum, o Papa Leão XIII condenara firmemente a exploração dos operários e os excessos cometidos em nome do liberalismo econômico. Assim, na última década do século XIX, os Estados iniciam a sua intervenção em questões de trabalho, normatizando limites de tempo, condições de segurança e higiene, e da jurisdição laboral (RAMALHO, 2009, p. 41/42). Amauri Mascaro Nascimento ressalta que, embora seja cronologicamente posterior a esse esforço sistemático de regulamentação e normatização, a CLT estava imbuída pelos mesmos ideais do humanismo cristão (2009, p. 59). A exposição de motivos da CLT refere expressamente à pacificação dos conflitos em nome de um espírito de equidade, levando à uma confraternização das classes econômicas:

É o diploma do idealismo excepcional do Brasil orientado pela clarividência 
genial de V. Exa., reajustando o imenso e fundamental processo de sua dinâmica econômica, nas suas relações com o trabalho, aos padrões mais altos de dignidade e de humanidade da justiça social.

É incontestavelmente a síntese das instituições políticas estabelecidas por V.

Exa. desde o início de seu governo...

A Consolidação representa, portanto, em sua substância normativa e em seu

título, neste ano de 1943, não um ponto de partida, nem uma adesão recente a uma doutrina, mas a maturidade de uma ordem social há mais de um decênio instituída, que já se consagrou pelos benefícios distribuídos, como também pelo julgamento da opinião pública consciente, e sob cujo espírito de equidade confraternizaram as classes na vida econômica, instaurando nesse ambiente, antes instável e incerto, os mesmos sentimentos de humanismo cristão que encheram de generosidade e de nobreza os anais da nossa vida pública e social.

A exposição de motivos da CLT ( Decreto-Lei $n^{\circ}$ 5.452), previsivelmente louvava a clarividência do então Presidente da República, e as instituições do chamado Estado Novo, mas sobretudo pretendia apresentar a maturidade de uma ordem social, uma confraternização entre adversários que teria trazido paz a um ambiente antes instável e incerto. De fato, como ressalta Nascimento, a Constituição de 1937 havia reagido à agitação no interior das fábricas proibido as greves e lockouts, rotulando-os como "recursos anti sociais, nocivos ao trabalho e ao capital” (2009, p. 59).

A exposição de motivos da CLT basicamente resume os pontos principais da encíclica Rerum Novarum, inclusive quanto à apologia da intervenção estatal em nome da manutenção dos “mandamentos da lei de Deus” e da "lei natural”. As leis devem refletir os “princípios e o sentimento religioso":

Em todo o caso, estamos persuadidos, e todos concordam nisto, de que é necessário, com medidas prontas e eficazes, vir em auxílio dos homens das classes inferiores, atendendo a que eles estão, pela maior parte, numa situação de infortúnio e de miséria imerecida. O século passado destruiu, sem as substituir por coisa alguma, as corporações antigas, que eram para eles uma proteção; os princípios e o sentimento religioso desapareceram das leis e das instituições públicas, e assim, pouco a pouco, os trabalhadores, isolados e sem defesa, têm-se visto, com o decorrer do tempo, entregues à mercê de senhores desumanos $\mathrm{e}$ à cobiça duma concorrência desenfreada. A usura voraz veio agravar ainda mais o mal. Condenada muitas vezes pelo julgamento da Igreja, não tem deixado de ser praticada sob outra forma por homens ávidos de ganância, e de insaciável ambição. 
O curso de ação proposto pela encíclica é a intervenção paternalista do Estado, cuja atuação é comparada à do chefe de família cristão, e da responsabilidade social dos patrões, enquanto provedores de empregos e cristãos:

Façam os governantes uso da autoridade protetora das leis e das instituições; lembrem-se os ricos e os patrões dos seus deveres; tratem os operários, cuja sorte está em jogo, dos seus interesses pelas vias legítimas; e, visto que só a religião, como dissemos no princípio, é capaz de arrancar o mal pela raiz, lembrem-se todos de que a primeira coisa a fazer é a restauração dos costumes cristãos, sem os quais os meios mais eficazes sugeridos pela prudência humana serão pouco aptos para produzir salutares resultados. Quanto à Igreja, a sua ação jamais faltará por qualquer modo, e será tanto mais fecunda, quanto mais livremente se possa desenvolver.

Condena-se veementemente o comunismo, que instigaria a inveja, a dissolução dos costumes dos trabalhadores, e, por fim, a dissolução do edifício social:

Os Socialistas, para curar este mal, instigam nos pobres o ódio invejoso contra os que possuem, e pretendem que toda a propriedade de bens particulares deve ser suprimida, que os bens dum indivíduo qualquer devem ser comuns a todos, e que a sua administração deve voltar para - os Municípios ou para o Estado. Mediante esta transladação das propriedades e esta igual repartição das riquezas e das comodidades que elas proporcionam entre os cidadãos, lisonjeiam-se de aplicar um remédio eficaz aos males presentes. Mas semelhante teoria, longe de ser capaz de pôr termo ao conflito, prejudicaria o operário se fosse posta em prática. Pelo contrário, é sumamente injusta, por violar os direitos legítimos dos proprietários, viciar as funções do Estado e tender para a subversão completa do edifício social.

Entre patrões e empregados deve prevalecer a fraternidade, considerada como dever cristão, exigência da condição comum como filhos de Deus:

Entre estes deveres, eis os que dizem respeito ao pobre e ao operário: deve fornecer integral e fielmente todo o trabalho a que se comprometeu por contrato livre e conforme à equidade; não deve lesar o seu patrão, nem nos seus bens, nem na sua pessoa; as suas reivindicações devem ser isentas de violências e nunca revestirem a forma de sedições; deve fugir dos homens perversos que, nos seus discursos artificiosos, lhe sugerem esperanças exageradas e lhe fazem grandes promessas, as quais só conduzem a estéreis pesares e à ruína das fortunas...

Mas é ainda demasiado pouco a simples amizade: se se obedecer aos preceitos do cristianismo, será no amor fraterno que a união se operará. Duma parte e doutra se saberá e compreenderá que os homens são todos absolutamente nascidos de Deus, seu Pai comum; que Deus é o seu 
único e comum fim, que só Ele é capaz de comunicar aos anjos e aos homens uma felicidade perfeita e absoluta; que todos eles foram igualmente resgatados por Jesus Cristo e restabelecidos por Ele na sua dignidade de filhos de Deus, e que assim um verdadeiro laço de fraternidade os une, quer entre si, quer a Cristo, seu Senhor, que é «o primogénito de muitos irmãos».

A fraternidade entre patrões e empregados não afasta a resignação dos menos favorecidos com a sua sorte, uma vez que a diferença seria inerente à condição humana e todos os esforços para a igualdade seriam fadados ao fracasso. Como no corpo humano, os indivíduos desempenham diferentes papeis e assim deve ser para que o organismo social funcione a contento:

O primeiro princípio a pôr em evidência é que o homem deve aceitar com paciência a sua condição: é impossível que na sociedade civil todos sejam elevados ao mesmo nível. É, sem dúvida, isto o que desejam os Socialistas; mas contra a natureza todos os esforços são vãos. Foi ela, realmente, que estabeleceu entre os homens diferenças tão multíplices como profundas; diferenças de inteligência, de talento, de habilidade, de saúde, de força; diferenças necessárias, de onde nasce espontaneamente a desigualdade das condições. Esta desigualdade, por outro lado, reverte em proveito de todos, tanto da sociedade como dos indivíduos; porque a vida social requer um organismo muito variado e funções muito diversas, e o que leva precisamente os homens a partilharem estas funções é, principalmente, a diferença das suas respectivas condições.

Por fim, atribui-se às associações, sejam elas entre empregados ou mistas com os empregadores o papel de se ampararem mutuamente em acidentes, enfermidades ou fraquezas. Ao comunismo, e a consequente abolição da propriedade privada, contrapõe a alternativa da proteção mútua:

Em último lugar, diremos que os próprios patrões e operários podem singularmente auxiliar a solução, por meio de todas as obras capazes de aliviar eficazmente a indigência e de operar uma aproximação entre as duas classes. Pertencem a este número as associações de socorros mútuos; as diversas instituições, devidas à iniciativa particular, que têm por fim socorrer os operários, bem como as suas viúvas e órfãos, em caso de morte, de acidentes ou de enfermidades; os patronatos que exercem uma protecção benéfica para com as crianças dos dois sexos, os adolescentes e os homens feitos. Mas o primeiro lugar pertence às corporações operárias, que abrangem quase todas as outras. Os nossos antepassados experimentaram por muito tempo a benéfica influência destas associações. Ao mesmo tempo que os artistas encontravam nelas inapreciáveis vantagens, as artes receberam delas novo brilho e nova 
vida, como o proclama grande quantidade de monumentos. Sendo hoje mais cultas as gerações, mais polidos os costumes, mais numerosas as exigências da vida quotidiana, é fora de dúvida que se não podia deixar de adaptar as associações a estas novas condições. Assim, com prazer vemos Nós irem-se formando por toda a parte sociedades deste gênero, quer compostas só de operários, quer mistas, reunindo ao mesmo tempo operários e patrões: é para desejar que aumentem a sua ação.

Em pleno século XXI, em que a simples ideia do ensino religioso nas escolas ou a manutenção de crucifixos em repartições públicas ofende a sensibilidade de muitos, é fácil retirar Deus da história. E descartar de plano a realização do Espírito, como proposto por Hegel como uma construção filosófica artificial baseada em fábulas bíblicas. Mais complexo é abandonar a crença de que existe um sentido unívoco na história, e somos conduzidos pela racionalidade em direção ao progresso.

A exposição de motivos da CLT basicamente previu o fim dos conflitos na seara trabalhista, sob os eflúvios do "espírito" de equidade, pacificando um ambiente "antes instável e incerto”. Como na teoria hegeliana, não houve uma vitória do capital ou do trabalho, mas uma reconciliação entre ambos, animados por iguais sentimentos de humanismo cristão, de “generosidade e nobreza”.

\section{Neoliberalismo e crítica ao Estado protecionista}

Setenta e quatro anos depois, não havia quaisquer sinais de espírito de equidade entre as classes, mas o obstáculo seria a atuação do Estado, somada à má qualidade das leis. A marcha vitoriosa do progresso social estaria sendo obstada justamente pela intervenção do Estado (através da Justiça do Trabalho, mais especificamente), somado à incerteza jurídica supostamente causada pela CLT. A atuação da Justiça do Trabalho obstando o êxito das negociações coletivas e negando validade à autonomia da vontade trariam uma insegurança jurídica, que seria a origem da crise econômica. A exposição de motivos da Lei $n^{\circ} 13.467$, de 13/07/2017 aposta em nova utopia de uma sociedade sem conflito, eliminando a intervenção estatal.

A suposta evolução das relações sociais (que já havia sido mencionada pela comissão copiladora da CLT) também é mencionada na nova lei. A mesma crença no progresso que trará o fim da história, formulado por Hegel, informa a nova lei. O humanismo cristão é aqui substituído pela democracia, cujos valores de respeito à diferença trariam a necessária maturidade social necessária ao consenso: 
O Brasil vem desde a redemocratização em 1985 evoluindo no diálogo social entre trabalhadores e empregadores. A Constituição Federal de 1988 é um marco nesse processo, ao reconhecer no inciso XXVI do art. $7^{\circ}$ as convenções e acordos coletivos de trabalho. O amadurecimento das relações entre capital e trabalho vem se dando com as sucessivas negociações coletivas que ocorrem no ambiente das empresas a cada data-base, ou fora dela.

A síntese entre os antípodas (capital e trabalho) seria trazida pela negociação coletiva, um espelho dos valores democráticos de respeito às diferenças. Categorias bem organizadas e com sindicatos fortes como bancários, metalúrgicos e petroleiros, seriam pioneiros na prevenção das lides trabalhistas:

Categorias de trabalhadores como bancários, metalúrgicos e petroleiros, dentre outras, prescindem há muito tempo da atuação do Estado, para promover-lhes o entendimento com as empresas. Contudo, esses pactos laborais vem tendo a sua autonomia questionada judicialmente, trazendo insegurança jurídica às partes quanto ao que foi negociado. Decisões judiciais vem, reiteradamente, revendo pactos laborais firmado entre empregadores e trabalhadores, pois não se tem um marco legal claro dos limites da autonomia da norma coletiva de trabalho.

O atual Presidente da Câmara dos Deputados, Rodrigo Maia, afirmou em março de 2017 que o “excesso de regras no mercado de trabalho gerou 14 milhões de desempregados” e que juízes tomariam decisões “irresponsáveis”, que teriam quebrado bares, restaurantes e hotéis no Rio de Janeiro e que a Justiça do Trabalho “não deveria nem existir”. As declarações foram reforçadas pelo próprio presidente do TST, Ministro Ives Gandra Martins Filho em evento realizado na Fecomércio em Maio de 2017. O Ministro afirmou que os "excessos protecionistas” da Justiça do Trabalho teriam criado a necessidade da reforma trabalhista e que o "ativismo judicial” seria fonte de insegurança jurídica, prejudicando os investimentos e a geração de empregos.

O velho argumento da obsolescência voltou ao cenário com os cortes orçamentários em 2015, ainda durante a Presidência de Dilma Rousseff. O relator geral do Orçamento da União de 2016, deputado Ricardo Barros (PP-PR) defendeu cortes de 50\% das dotações para custeio e de $90 \%$ para investimentos, atingindo de maneira seletiva o judiciário trabalhista. Em seu relatório, debatido na sessão da Comissão Mista de Orçamento, o parlamentar sustentou que a Justiça do Trabalho é "condescendente com os trabalhadores e que as leis trabalhistas precisam ser modernizadas”. Ainda em seu relatório, o deputado Ricardo Barros afirmou que 
“atualmente, mesmo um profissional graduado e pós-graduado, com elevada remuneração, é considerado hipossuficiente na Justiça do Trabalho. Pode alegar que desconhecia seus direitos e era explorado e a Justiça tende a aceitar sua argumentação”. Embora a proposta de Barros não tenha sido aprovada em sua totalidade, ainda assim a Justiça do Trabalho foi a mais prejudicada com os cortes. Perdeu 90\% nos investimentos e 30\% nas verbas de custeio, enquanto nos demais ramos do Judiciário os cortes foram de 40\% e 15\% nas duas áreas.

Esses cortes seletivos refletem a crença neoliberal de que a intervenção estatal é sempre desastrosa, e tanto mais calamitosa quando o magistrado exerce seu ofício jurisdicional. Especificamente a Justiça do Trabalho foi eleita como paradigma do atraso e morosidade, embora as estatísticas do Conselho Nacional de Justiça demonstrem que o Judiciário de maneira geral gasta mais do que arrecada.

Segundo dados estatísticos do Conselho Nacional de Justiça, em 2015 a Justiça do Trabalho corresponde a apenas $10 \%$ das unidades judiciárias do total do Poder Judiciário no Brasil (CNJ, 2016, p. 31). A Justiça Estadual corresponde à maior despesa nos gastos gerais do Poder Judiciário (56,4\% do orçamento geral) nas estatísticas do CNJ (2016, p. 33). Os custos da manutenção da máquina judiciária somaram $\mathrm{R}$ \$9,2 bilhões, com um custo de $\mathrm{R}$ \$387, 56 por habitante, com crescimento médio na ordem de 3,8\% ao ano (CNJ, 2016, p. 33). Os valores estratosféricos, contudo, representam apenas 2,6\% dos gastos totais da União, Estados, Municípios e Distrito Federal. Contrariando o senso comum, não se trata de mau planejamento ou de gastos suntuários, mas de gastos com pessoal (89\%), entre magistrados, servidores, inativos e terceirizados (CNJ, 2016, p. 33). As despesas com equipamentos e programas sofreram deflação no ano de 2015, sofrendo perda de 34,4\% em relação aos períodos anteriores.

Em relação à eficiência, apenas a Justiça Federal arrecada mais do que gasta (240\%), enquanto todos os demais ramos custam mais aos cofres públicos do que arrecadam. A Justiça Estadual recupera apenas 40\% do que gasta, a Justiça do Trabalho arrecada 16\% do seu custo (CNJ, 2016, p. 35). Em uma análise de custo/benefício, os extremos são os tribunais superiores e militares, cujas receitas correspondem apenas a $2 \%$ e $1 \%$, respectivamente, de suas despesas.

Os índices de conciliação do judiciário trabalhista são os maiores do judiciário (25\%), muito superiores ao segundo colocado (a Justiça Estadual), que apresenta percentual de apenas 9\% (CNJ, 2016, p. 46). A recorribilidade externa atingiu 52,8\%, superando a Justiça Federal (com 34,2\%) e a Justiça Estadual (9,5\%) (CNJ, 2016, p.46). Apesar dos altos índices de 
O LOBO VEGETARIANO E O CORDEIRO NO BANQUETE DE FORRAGEM: A UTOPIA

DA SUPERAÇÃO DO ANTAGONISMO ENTRE CAPITAL E TRABALHO

recorribilidade, o congestionamento da Justiça do Trabalho é de 54,2\%, inferior ao das justiças Estadual (74,8\%), Federal (71,6\%) e Superior (54,5\%) (CNJ, 2016, p. 49)

No ano de 2015, as despesas totais da Justiça do Trabalho somaram aproximadamente R\$ 16,5 bilhões, o que representou um crescimento de 4,9\% em relação ao ano de 2014, e de 9,0\% no período 2009-2015. Essa despesa equivale a 0,28\% do Produto Interno Bruto (PIB) nacional, a 0,72\% dos gastos totais da União e a um custo pelo serviço de Justiça de $\mathbf{R} \mathbf{\$} \mathbf{8 0 , 6 4}$ por habitante. Este último indicador teve pequenas variações desde 2009 (2,1\%), (CNJ, 2016, p. 158). Assim sendo, a autonomia da Justiça do Trabalho não representa um desafio ao equilíbrio das contas públicas. Ou um obstáculo à conciliação, visto que apresenta os mais elevados índices de conciliação.

Números à parte, as criticas do presidente da Câmara e do Relator Geral do Orçamento apenas repetem o credo neoliberal de que quanto menor o Estado, melhor. O economista Luiz Carlos Bresser Pereira, Ministro da Fazenda durante a presidência de José Sarney afirmou que a grande tarefa política dos anos 90 seria a reforma ou a reconstrução do Estado. Sustentou que, entre os anos 30 e os anos 60 deste século, o Estado teria sido um fator de desenvolvimento econômico e social. A partir dos anos 70, porém, o crescimento “distorcido” do Estado teria causado a redução das taxas de crescimento econômico, a elevação das taxas de desemprego e do aumento da taxa de inflação. Bresser Pereira aponta uma “onda neoconservadora” e reformas econômicas orientadas para o mercado que teriam sido a resposta a esta crise. O autor descartou o Estado Mínimo como inviável, porém defendeu uma “reconstrução do Estado - para que este pudesse realizar não apenas suas tarefas clássicas de garantia da propriedade e dos contratos, mas também seu papel de garantidor dos direitos sociais e de promotor da competitividade do seu respectivo país” (BRESSER PEREIRA, 1997, p. 1).

A apologia do mercado certamente não era nova na década de 90. Já era defendida por Adam Smith, considerado o fundador da Economia Clássica. Nos anos 90 recebe o incentivo necessário para o seu ressurgimento com o início do processo de globalização. Assim é que os economistas neoliberais retomaram as formulações de Adam Smith no sentido de que "o mercado é o mecanismo de alocação eficiente de recursos por excelência, mas mesmo nesta tarefa sua ação deixa muitas vezes a desejar” (BRESSER PEREIRA, 1997, p. 10). BRESSER PEREIRA inclusive reconhece que a crise dos anos 30 se originou no mau funcionamento do mercado, por influência do pensamento keynesiano (1997, p. 11). Da crença na eficiência do 
mercado em contraposição à uma suposta incompetência do Estado, decorre a consequência de que o Estado seria "incapaz" de atender com qualidade as demandas sociais (BRESSER PEREIRA, 1997, p. 13). Ainda segundo Bresser Pereira, a crise dos anos 80 não teria mais como causa a insuficiência crônica de demanda de que falava Keynes, e sim a atuação do Estado (1997, p. 12). Na opinião do autor, agora a crise econômica seria devida à crise do Estado - do Estado Intervencionista, que, de fator do desenvolvimento, ter-se-ia transformado em obstáculo (BRESSER PEREIRA, p. 12). O novo Estado, “reformado” seria meramente gerencial, e não mais burocrático. Não prestaria os serviços diretamente mediante emprego de "burocratas estatais” (BRESSER PEREIRA, 1997, p. 15). Dentro dessa linha de raciocínio, não caberia ao Judiciário emitir juízos de valor sobre os contratos de trabalho.

O real incômodo é a discricionariedade judicial. Quando a exposição de motivos se refere a ativismo, refere-se claramente a discricionariedade, a disparidade entre os julgados, que seria a origem da insegurança jurídica. O tópico seguinte da exposição de motivos da lei de Reforma Trabalhista critica justamente a interferência do judiciário trabalhista sobre a liberdade contratual:

A discussão da hipossuficiência foi recentemente objeto de análise do Supremo Tribunal Federal, quando julgou a ação contra o plano de dispensa incentiva do BESC/Banco do Brasil, na discussão do RE 590415 / SC. O Ministro Luís Roberto Barroso em seu voto sustenta que "no âmbito do direito coletivo, não se verifica, portanto, a mesma assimetria de poder presente nas relações individuais de trabalho. Por consequência, a autonomia coletiva da vontade não se encontra sujeita aos mesmos limites que a autonomia individual." Prossegue o Ministro em seu voto destacando que "embora, o critério definidor de quais sejam as parcelas de indisponibilidade absoluta seja vago, afirma-se que estão protegidos contra a negociação in pejus os direitos que correspondam a um "patamar civilizatório mínimo", como a anotação da CTPS, o pagamento do salário mínimo, o repouso semanal remunerado, as normas de saúde e segurança do trabalho, dispositivos antidiscriminatórios, a liberdade de trabalho etc. Enquanto tal patamar civilizatório mínimo deveria ser preservado pela legislação heterônoma, os direitos que o excedem sujeitar-se-iam à negociação coletiva, que, justamente por isso, constituiria um valioso mecanismo de adequação das normas trabalhistas aos diferentes setores da economia e a diferenciadas conjunturas econômicas."

4. Essas discussões demonstram a importância da medida ora proposta, de valorização da negociação coletiva, que vem no sentido de garantir o alcance da negociação coletiva e dar segurança ao resultado do que foi pactuado entre trabalhadores e empregadores. 


\section{O LOBO VEGETARIANO E O CORDEIRO NO BANQUETE DE FORRAGEM: A UTOPIA DA SUPERAÇÃO DO ANTAGONISMO ENTRE CAPITAL E TRABALHO}

Pela leitura dos parágrafos supra, depreende-se que se pretende retirar da Justiça do Trabalho a possibilidade de revisão dos acordos realizados entre os representantes dos empregados e empregadores, e com isso prestigiar os ditos acordos:

5. Outra medida ora proposta, que visa prestigiar o diálogo social e desenvolver as relações de trabalho no país, é a regulamentação do art. 11 da Constituição Federal. Esse dispositivo constitucional assegura a eleição de um representante dos trabalhadores nas empresas com mais de duzentos empregados, com a missão de promover o entendimento direto com a direção da empresa. O representante dos trabalhadores no local de trabalho deverá atuar na conciliação de conflitos trabalhistas no âmbito da empresa, inclusive os referentes ao pagamento de verbas trabalhistas periódicas e rescisórias, bem como participar na mesa de negociação do acordo coletivo de trabalho com a empresa.

6. A experiência européia demonstra a importância da representação laboral na empresa. Países como Alemanha, Espanha, Suécia, França, Portugal e Reino Unido possuem há vários anos as chamadas comissões de empresa ou de fábrica. A maturidade das relações de trabalho em alguns países europeus propicia um ambiente colaborativo entre trabalhador e empresa, resultando na melhoria do nível de produtividade da empresa.

Nos parágrafos supra, percebe-se claramente a discrepância entre a realidade e o discurso. Em primeiro lugar, porque em razão do princípio da inafastabilidade da jurisdição (art. 50, XXXV), o judiciário ainda poderia ser provocado a examinar a validade de quaisquer ajustes entre comissões mistas de empregadores e empregados. Por se tratar de cláusula pétrea, o fechamento dessa via de intervenção estatal sobre a autonomia privada não poderia ser feito por lei ordinária, tornando inócua a Reforma Trabalhista neste aspecto. Ainda que se criassem óbices ao acesso à jurisdição, tais como o pagamento antecipado de custas e emolumentos, não existe garantia alguma de que haveria uma uniformização da jurisprudência no sentido de sempre validar a autonomia da vontade nos contratos de trabalho.

No parágrafo seguinte, a exposição de motivos explicita a tese de que a judicialização dos conflitos seria resultado do "ativismo" dos juízes trabalhistas. Inadvertidamente, contradiz a própria tese de que a má qualidade das leis e a discricionariedade dos julgados seriam 
responsáveis pela quantidade de ações trabalhistas, ao aceitarem os dados de que a maioria das ações versa sobre verbas resilitórias:

7. No Brasil temos um nível elevado de judicialização das relações do trabalho, o que é retratado pela quantidade de ações trabalhistas que anualmente dão entrada na Justiça do Trabalho. Na grande maioria da ações trabalhistas a demanda reside no pagamento de verbas rescisórias. A falta de canais institucionais de diálogo nas empresas que promovam o entendimento faz com que o trabalhador só venha a reivindicar os seus direitos após o término do contrato de trabalho. Com isso, problemas que poderiam ser facilmente resolvidos no curso do contrato de trabalho vão se acumulando, para serem discutidos apenas ao término do vínculo empregatício, na Justiça do Trabalho.

8. A regulamentação do art. 11 da Constituição da República tornará possível o aprimoramento as relações de trabalho no país, ao instituir no ambiente da empresa um agente com credibilidade junto ao trabalhador, já que ele será escolhido dentre os empregados da empresa, independentemente de filiação sindical, com quem ele poderá contar para mediar a resolução de conflitos individuais havidos no curso da relação empregatícia. A atuação do representante dos trabalhadores trará ganhos para a empresa, na medida que ela poderá se antecipar e resolver o conflito, antes que o passivo trabalhista se avolume e venha a ser judicializado.

Se a maior parte das ações efetivamente versa sobre verbas resilitórias e não sobre uma eventual discussão sobre a validade das cláusulas de contratos de trabalho individuais, certamente não há de questionar a qualidade das leis ou a suposta irresponsabilidade das decisões.

De qualquer sorte, a cronologia da criação da Justiça do Trabalho desmente a tese de que seria responsável pela judicialização das relações de trabalho. Em 1932 foram instituídos as Juntas de Conciliação e Julgamento e as Comissões Mistas de Conciliação, visando a dirimir controvérsias individuais e coletivas, respectivamente (DAMASCENO, 2002, p. 12). Essas primitivas Juntas não possuíam autonomia, uma vez que suas decisões poderiam ser revogadas pelo Ministro do Trabalho e só podiam ser executadas na Justiça Civil, onde havia a possibilidade de serem declaradas nulas (DAMASCENO, 2002, p. 12). Apenas em maio de 1941, a Justiça do Trabalho adquiriu autonomia, embora seus juízes apenas adquirissem as garantias próprias da magistratura em setembro de 1946 (DAMASCENO, 2002, p. 12).

Assim sendo, tanto a subordinação da Justiça do Trabalho à Justiça Estadual e o julgamento das lides trabalhistas pelas regras do direito comum já foram experimentadas, sem 


\section{O LOBO VEGETARIANO E O CORDEIRO NO BANQUETE DE FORRAGEM: A UTOPIA DA SUPERAÇÃO DO ANTAGONISMO ENTRE CAPITAL E TRABALHO}

qualquer êxito quanto à redução dos conflitos. Muito antes pelo contrário. O Decreto-Lei $\mathrm{n}^{\circ}$ 5.452, de $1^{\circ}$ de Maio de 1943 (a Consolidação das Leis do Trabalho), é inclusive posterior a ambas, interregno no qual a agitação nas fábricas se radicalizou a ponto de provocar a intervenção do Poder Público, outorgando uma legislação própria protetiva dos interesses dos trabalhadores.

\section{O leão vegetariano e a falta de forragem}

O conflito pode ser tratado de forma adequada tanto pela prevenção, quanto pela gestão e pela via da resolução (ORSINI, p. 147). A prevenção de conflitos na esfera trabalhista se daria pela prevenção dos riscos profissionais, proporcionando um ambiente de trabalho mais seguro e agradável (ORSINI, p. 148). O segundo nível de atuação (a gestão) ocorreria quando o conflito não está suficientemente maduro para ser resolvido. O terceiro nível de solução de conflitos (a resolução) poderia ocorrer pela autotutela, autocomposição e heterocomposição (ORSINI, p. 148). Ora, a jurisdição é o poder que o Estado avocou para si de dizer o direito, de fazer justiça, em substituição aos particulares (ORSINI, p. 150). A jurisdição existe para evitar que o conflito degenere em violência, transformando adversários em inimigos (ORSINI, p. 153).

Não é o acesso à jurisdição que cria os conflitos. Como salientamos no início deste artigo, não basta que o leão renuncie a seus hábitos predatórios, é necessário que a forragem alimente a todos. Os conflitos do trabalho se originam da escassez de postos de trabalho com salários condignos em condições decentes. As mudanças tecnológicas, o aumento da competitividade e a necessidade de redução dos custos que criam novos impasses nas relações de trabalho (LOCKMANN, p. 131). É por conta desse cenário de rápidas mudanças que vem aumentando vertiginosamente o número de demandas judiciais (LOCKMANN, p. 131).

As micro e pequenas empresas constituem 99,2\% dos empreendimentos, 57,2\% dos empregos, mas apenas 26,0\% da massa salarial (ZANGARI JUNIOR, 2007, p. 20). 58\% dos microempreendimentos são considerados de baixa renda (BEDÊ, 2015, p. 10). 85\% dos donos de negócio atuam por conta própria e apenas 15\% empregam. Estes empreendimentos de "uma pessoa só” geridos pelo próprio dono envolvem, em geral, estruturas simples de operação, assim como também podem representar maior precariedade, fazendo com que o negócio dependa quase que exclusivamente do dono. No grupo dos donos de negócio de baixa renda, a parcela de conta-própria sobe para 96\%, ou seja, apenas 4\% são empregadores. Entre os donos de negócio que possuem média renda, a proporção de conta-própria é de 77\% e a de empregadores 
é de 23\%. No grupo dos que possuem alta renda, a proporção de empregadores é de $43 \%$. Estes dados revelam que a passagem da baixa renda para a alta renda é acompanhada pelo aumento da proporção de empregadores (BEDÊ, 2015, p. 10). A Reforma Trabalhista aprofunda a distância entre as grandes e as micro empresas, porque além de manter uma lei única, pensada para estabelecimentos com mais de dez empregados, acrescenta a comissão de empregados e empregadores. A maioria dos empregos está nos pequenos negócios (57,2\%), no âmbito dos quais não se concebe como poderia ser efetiva uma comissão mista de empregadores e empregados.

O conflito é inerente à existência em sociedade. Uma sociedade sem conflito é uma utopia ou um pesadelo totalitário. Afirmar que a Justiça do Trabalho não deveria sequer existir é confundir o efeito (litigiosidade) com a causa (escassez de vagas de emprego). Os conflitos são gerados pelas mudanças no mundo do trabalho que excluem vagas no mercado laboral formal e condenam milhares a sobreviver distribuindo propaganda impressa, vendendo objetos nos semáforos ou estimulando a caridade (NALINI, p. 269). Aos desqualificados juntam-se os mais velhos, os excessivamente jovens, ou simplesmente incapazes de se adaptar ao mercado de trabalho que demanda escolaridade, versatilidade e mobilidade. Tais pessoas simplesmente carecem de importância econômica, nem mesmo como exército industrial de reserva.

O magistrado trabalhista de fato não se percebe como mediador imparcial dos conflitos, mas como vetor de mudanças sociais (DELEITO 2017, p. 125). É questionável a eficácia do judiciário trabalhista na solução de conflitos. A postura protecionista inclusive exacerba os conflitos. A gratuidade de justiça e a ausência de penas por litigância de má-fé estimularam aventuras judiciárias. Por outro lado, acreditar que a extinção da Justiça do Trabalho traria o fim dos conflitos representa uma ingenuidade ou uma utopia.

A Lei $n^{\circ}$ 13.467/2017 nada dispõe sobre o ônus da prova. Ainda que tivesse destinado vários artigos sobre o tema não teria como impedir a discricionariedade do judiciário. Nenhuma lei, por mais detalhada que seja, pode amordaçar o judiciário, e transformá-lo em mero autômato repetidor das determinações emanadas do Poder Legislativo. O postulado de Montesquieu de que os juízes não passariam de boca das palavras lei, seres inanimados, incapazes de moderar - lhes a força ou o rigor $^{2}$, sonho de consumo de qualquer congressista,

2

"Les juges de la nation se sont que la bouche qui prononce les paroles de la loi, des êtres inanimés, qui n'em peuvent modérer ni la force ni la rigueur” in MONTESQUIEU, De l'esprit des lois, Flammarion, Paris, 2013, disponível em http://montesquieu.ens-lyon.fr/IMG/pdf/de-l-esprit-des-lois.pdf, 
nunca saiu do terreno das ideias. Juízes são humanos e, portanto, imprevisíveis em suas decisões, e não há lei capaz de impedi-los de decidir conforme suas conviç̧ões pessoais. Nesse sentido, não há diferença entre um juiz trabalhista e um civilista. Nem meios para o legislador inviabilizar a discricionariedade do judiciário. A extinção da Justiça do Trabalho seria inócua simplesmente porque nunca existiu um juiz “boca das palavras da lei”.

A redução da litigiosidade não significa a pacificação dos conflitos e sim o aumento do risco com a escolha da via judicial. A exposição de motivos da Lei de Reforma Trabalhista pretende tornar a Justiça do Trabalho despicienda, citando os bancários e metalúrgicos como exemplos bem sucedidos de autocomposição. Entretanto, toda a força e combatividade do sindicato dos bancários não logrou êxito em limitar a terceirização das atividades bancárias, e a consequente precarização das condições de trabalho, ou o desemprego causado pelo internet banking. O Presidente da Confederação Nacional dos Metalúrgicos (filiada à CUT) já inclusive conclamou a necessidade de resistência e enfrentamento da reforma.

Em resumo, a Lei de Reforma Trabalhista propõe uma utopia de um mercado de trabalho que se autorregula e, por conseguinte, prescinde da intervenção estatal. Como a CLT que se propunha a conciliar trabalho e capital sob a égide do humanismo cristão, a nova lei pretende alcançar o fim dos conflitos pelo consenso racional construído nas comissões mistas de empregados e empregadores. O artificialismo da solução salta aos olhos. Conflitos surgem da escassez de recursos, de empregos dignos, não da ausência de diálogo ou respeito ao outro. Ainda que fossem criados óbices ao exercício da jurisdição, tais como o fim da gratuidade de justiça e a extinção das Varas do Trabalho no interior e postos avançados, os conflitos continuariam a existir. Com a agravante de que, obstada a via judicial, podem degenerar em violência, os mais fortes fazendo valer seus direitos em detrimento dos mais frágeis.

\section{Bibliografia:}

ARENDT, Hannah, A vida do espírito, 4a edição, Relume Dumará, Rio de Janeiro, 2000.

BRASIL, Consolidação das leis do trabalho comentada, disponível em http://siabi.trt4.jus.br/biblioteca/direito/legislacao/codigos/clt/Prunes_CLT_comentada_\%202 006.pdf, acesso em 05/10/2017.

BARBOSA, Bruna Rangel et MARCONDES FILHO, Clélio, Como o protecionismo da Justiça Trabalhista impede o crescimento da empresa, Revista Univap, v. 22, n.40, 2016, 
disponível

em

$<$ http://revista.univap.br/mwginternal/de5fs23hu73ds/progress?id=naDAIDEXI-QPyDUWjrYEsijd2N7QB3rXTHaKLXTIOo>,acesso em 09/10/2017.

BEDÊ, Marco Aurélio, Os donos de negócio no Brasil: análise por faixa de renda (20032013), Brasília, Sebrae, 2015, disponível em http://www.bibliotecas.sebrae.com.br/chronus/ARQUIVOS_CHRONUS/bds/bds.nsf/5233f8a 3bfff4044344918255d387502/\$File/5772.pdf, acesso em 11/10/2017.

CALHÃO FILHO, Luiz Antonio V, A nova era trabalhista: uma abordagem histórica do Direito do Trabalho, sua evolução e seu futuro após a Reforma Trabalhista, São Paulo, LTR, 2018.

DAMASCENO, Fernando Américo Veiga. Direito, processo e justiça do trabalho: princípios e perspectivas, São Paulo, Manole, 2002.

DELEITO, Hilda Baião Ramírez, A desconsideração da personalidade jurídica na justiça do trabalho, Curitiba, Appris, 2017.

HARTMAN, Tim, $\mathbf{O}$ economista clandestino ataca novamente: como arrumar ou arruinar uma economia, Rio de Janeiro, Record, 2016.

HEGEL, Georg Wilhelm Friedrich, The philosophy of history, Batoche Books, Kitchener, 2001, disponível em http://www.dominiopublico.gov.br/download/texto/mc000120.pdf, acesso em 05/10/2017.

LEÃO XIII, Carta encíclica Rerum Novarum, disponível em http://w2.vatican.va/content/leoxiii/pt/encyclicals/documents/hf_l-xiii_enc_15051891_rerum-novarum.html, acesso em 02/04/2018.

LOCKMANN, Ana Paula Pellegrina, Sistema de soluções de conflitos - a importância de fomentar a cultura da conciliação, in PIMENTA, Adriana Campos de Souza et LOCKMANN, Ana Paula Pellegrina, Conciliação judicial individual e coletiva e formas extrajudiciais de solução dos conflitos trabalhistas, São Paulo, LTr, 2014.

MONTESQUIEU, De l'esprit des lois, Flammarion, Paris, 2013, disponível em http://montesquieu.ens-lyon.fr/IMG/pdf/de-l-esprit-des-lois.pdf, acesso em 18/10/2017.

NALINI, José Renato, Fabricar a cultura da paz, in PIMENTA, Adriana Campos de Souza et LOCKMANN, Ana Paula Pellegrina, Conciliação judicial individual e coletiva e formas extrajudiciais de solução dos conflitos trabalhistas, São Paulo, LTr, 2014 
O LOBO VEGETARIANO E O CORDEIRO NO BANQUETE DE FORRAGEM: A UTOPIA DA SUPERAÇÃO DO ANTAGONISMO ENTRE CAPITAL E TRABALHO

ORSINI, Adriana Goulart de Sena, Acesso à justiça, solução de conflitos e a política pública de tratamento adequado de conflitos trabalhistas, in PIMENTA, Adriana Campos de Souza et LOCKMANN, Ana Paula Pellegrina, Conciliação judicial individual e coletiva e formas extrajudiciais de solução dos conflitos trabalhistas, São Paulo, LTr, 2014.

SOARES, Saulo Cerqueira de Aguiar Soares, Direitos fundamentais do trabalho, São Paulo, LTr, 2017.

RAMALHO, Maria do Rosário Palma. Direito do Trabalho - Parte I, Dogmática Geral. Coimbra: Almedina, 2009.

SCALDAFERro, Maikon Chaider Silva, Hegel e o fim da história, disponível em http://www.uece.br/polymatheia/dmdocuments/polymatheiav5n8_hegel_fim_historia.pdf, acesso em 05/10/2017.

SEVERIANO, Adneison, Número de processos na Justiça do Trabalho no Amazonas reduz mais de 50\% depois da reforma trabalhista, disponível em https://g1.globo.com/am/amazonas/noticia/n-de-processos-na-justica-do-trabalho-no-amreduz-mais-de-50-apos-reforma-trabalhista.ghtml, acesso em 01/04/2018.

ZANGARI JÚNIOR, Jurandir, O direito do trabalho e as pequenas e microempresas: uma proposta de tratamento jurídico diferenciado, Pontifícia Universidade Católica, São Paulo, disponível em http://www.dominiopublico.gov.br/download/teste/arqs/cp041158.pdf, acesso em $11 / 10 / 2017$. 